\title{
Chronic cervicitis: role of adult autologus stem cells
}

\author{
Mayank Jain ${ }^{1}$, Sapna Jain ${ }^{2 *}$ \\ ${ }^{1}$ Department of Autologus Stem Cells, Obstetrics and Gynecology, Stem Cell Medicare Centre, New Delhi, India \\ ${ }^{2}$ Department of Obstetrics and Gynecology, LN Medical College, Bhopal, Madhya Pradesh, India
}

Received: 16 April 2017

Revised: 03 May 2017

Accepted: 05 May 2017

\author{
*Correspondence: \\ Dr. Sapna Jain, \\ E-mail: sapna.bajaj48@yahoo.com
}

Copyright: () the author(s), publisher and licensee Medip Academy. This is an open-access article distributed under the terms of the Creative Commons Attribution Non-Commercial License, which permits unrestricted non-commercial use, distribution, and reproduction in any medium, provided the original work is properly cited.

\section{ABSTRACT}

Background: Stem cells are biological cells found in all multi-cellular organisms and capable to differentiate into diverse specialized cell types and self-renew to produce more stem cells. Stem cells act as immuno-modulatory, angiogenetic, cell repairing and cell protecting agents. They also have strong anti-inflammatory effect due to paracrine action of trophic factors release. Chronic cervicitis is very common disease of adult women worldwide, chronic infection and inflammation of the cervix is hard to cure with high recurrence rate leading to long term consequences like pelvic inflammatory disease, infertility, ectopic pregnancy, chronic pelvic pain, increased predisposition to HPV and HIV infection and even can be a precursor of cervical cancer.

Methods: To show the therapeutic and symptomatic benefits of these cells in chronic cervicitis we injected 10 patients with adult autologus stem cells (AASCs) locally in the cervix, and PRP, growth factors IV. All the cells were harvested from bone marrow after bone marrow aspiration.

Results: Clinical benefits were evident on follow up visits in the entire treated patient. All the patient had shown improvement in symptoms like continuous malodourous discharge, dyspariunea, pelvic pain and pressure, backache, itching and burning, post coital bleeding.

Conclusions: Present study have shown that AASCs and growth factors is a safe effective ethical and viable option not only to cure the disease but also in improving the quality of life of a woman and protecting her from its significant consequences.

Keywords: AASCs, Cancer cervix, Chronic cervicitis, Growth factors, PRP

\section{INTRODUCTION}

Chronic cervicitis is a very common disease affecting adult women's physical and mental health and is predisposing condition for HPV, HIV infection and cervical cancer which is the most common cancer of female 1, 2 This problem affects women of both developing as well as developed countries equally though the etiological factors may be different.

It is clinically manifested as continuous greyish malodorous discharge per vaginum, dyspareunia, feeling of pain, pressure and heaviness in perineum, backache, post coital bleeding, burning and itching in vaginal area and general sense of weakness.

\section{Causes}

Infective

Sexually transmitted diseases like Chlamydia, Gonorrhoea, Trichomonas Vaginalis, viral infections like HSV and HPV. 
Non-infective

Allergy and irritation by chemical or physical means like IUCD, contraceptive diaphragm, cap, condom, tampon, douches, wash, spermicidal etc. Malnutrition, poor immunity and hygiene, multiple partners, early age of sexual activity. Commonly occurs after child birth and D and $\mathrm{C}$ procedure 2.

\section{Pathophysiology}

Mucus membrane of cervical canal is rugose and glands racemose type so once pathogen enter into the depth of glands becomes difficult to eradicate and act as a focal abscess. Pus and mucus act like chemical irritant leading to inflammation and therefore erosions, ectropion and nabothian cyst formation. Bacterial and hormonal imbalance also interferes with the body's ability to maintain healthy cervical tissue.

\section{Investigation}

- Per speculum examination-hypertrophied, erythematus, edematous, often eroded cervix with Nabothion cyst and discharge, signs of erosion of cervix and old lacerations from child birth evident.

- Pap smear shows inflammatory cellular infiltrate.

- Cervical biopsy-chronic inflammatory infiltrates, erosion, ectropion, and nabothion cyst.

- Colposcopy-evidence of erosion, increased vascularity, Lugols iodine negative and no acetic acid uptake shows non-malignant nature.

- High Vaginal Swab-for culture and sensitivity mostly inconclusive.

\section{Treatment options}

Varies from patient to patient and requires repeated course of local and systemic antibiotics and probiotics, antiviral, antifungal and interventions like cryosurgery to freeze abnormal cells, chemical cauterization to destroy abnormal cells. Diathermy, laser, conisation, LEEP, treatment of partner and finally hysterectomy.

\section{Significance of cervicitis}

Besides its troublesome symptoms leading to decreased quality of life and long term serious consequences like PID, CPP, infertility, ectopic pregnancy and severely impaired physical and mental health of women, it increases incidence of HIV and HPV. This long-standing inflammation can lead to cervical cancer. ${ }^{2,3}$

When the existing modalities of treatment did not give long term satisfactory result we decided to treat patients with Adult Autologous Stem cells and growth factors.

\section{METHODS}

After history, pelvic examination, routine and specific investigations, 10 married multiparus women of 30-45 years age group with diagnosed chronic cervicitis (Table 1) were studied during the period of December 2012 till January 2014. Patients were explained about the procedure in detail its beneficial outcome and side effects. With due ethical consideration, written and informed consent was taken for the procedure.

Table 1: Symptoms before treatment.

\begin{tabular}{|lllllll|}
\hline S.N. & $\begin{array}{l}\text { Continuos malodour } \\
\text { discharge PV }\end{array}$ & Dyspariunea & $\begin{array}{l}\text { Pelvic pain } \\
\text { and pressure }\end{array}$ & Backache & $\begin{array}{l}\text { Itching and } \\
\text { burning }\end{array}$ & $\begin{array}{l}\text { Post coital } \\
\text { bleeding }\end{array}$ \\
\hline Patient 1 & Excess & Yes & Severe & Moderate & Yes & Yes \\
\hline Patient 2 & Moderate & Yes & Severe & Moderate & Yes & Yes \\
\hline Patient 3 & Excess & Yes & Severe & Moderate & Yes & No \\
\hline Patient 4 & Excess & Yes & Severe & Moderate & yes & No \\
\hline Patient 5 & Moderate & Yes & Severe & Moderate yes & Yes \\
\hline Patient 6 & Mild & Yes & Moderate & Moderate yes & No \\
\hline Patient 7 & Excess & Yes & Moderate & Moderate yes & Yes \\
\hline Patient 8 & Excess & Occasional & Severe & Moderate yes & No \\
\hline Patient 9 & Moderate & Occasional & Moderate & Moderate yes & No \\
\hline Patient 10 & Excess & Yes & Severe & Severe & yes & Yes \\
\hline
\end{tabular}

Around $200 \mathrm{ml}$ of Autologus bone marrow was harvested from PSIS under LA and collected in marrow bag (Figure 1). Took to lab, fat and BM particles were removed.

Cells Isolated, processed and around $8 \mathrm{ml}$ buffy coat (Figure 2) was prepared for injection in to the defected cervical tissue at 4 sites. Remaining marrow was collected in a blood bag after double filtration for IV infusion too. 3 sittings were given at 3-4 weeks' interval. Patients were asked for regular follow up at 15 days interval initially then 3,6 , and 12 months. 


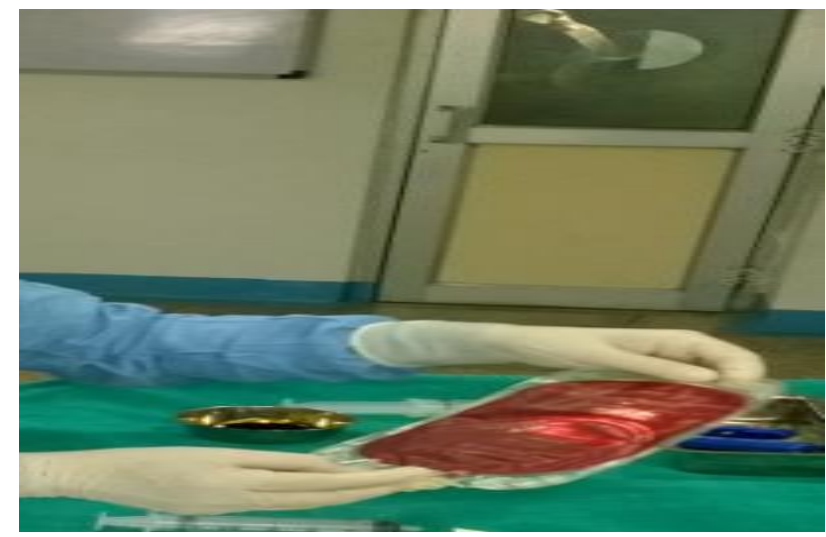

Figure 1: Bone marrow harvested in OT with all aseptic precautions from PSIS and stored in marrow bags (haematopoietic stem cells).

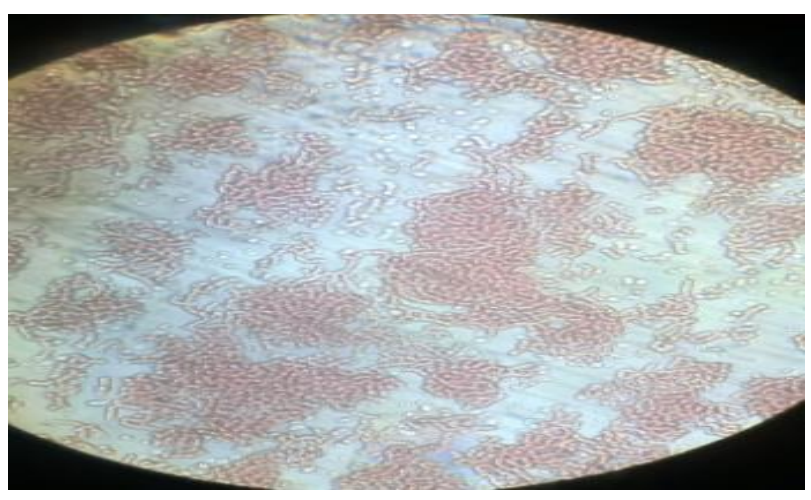

Figure 2: inverted microscope view of buffy coat prepared in laboratory, mononuclear cells are of haematopoietic cell lines which are further confirmed in flow cytometry.

\section{Inclusion criteria}

- Married, multiparus women of 35 to 45 years, post menstrually and no H/O medical illness.

\section{Exclusion criteria}

- Unmarried, elderly, prolapse uteri, major medical illness and post-menopausal.

\section{RESULTS}

Clinical benefits were evident on follow up visits in the entire treated patient (Figure 3). Tremendous improvement in mal-odorus discharge in 9 patients and 1 patient showed moderate improvement. All 5 patients were cured for post coital bleeding. For dyspareunia 9 patients showed improvement and 1 patient has persistence of it. In pelvic pressure pain and heaviness 8 patient showed complete improvement and 2 patients had mild improvement. All patients improved in their itching and burning. In backache 8 pt. got complete improvement and 2 patients had moderate relief which improved over the period. Postcoital bleeding got stopped in all patients.

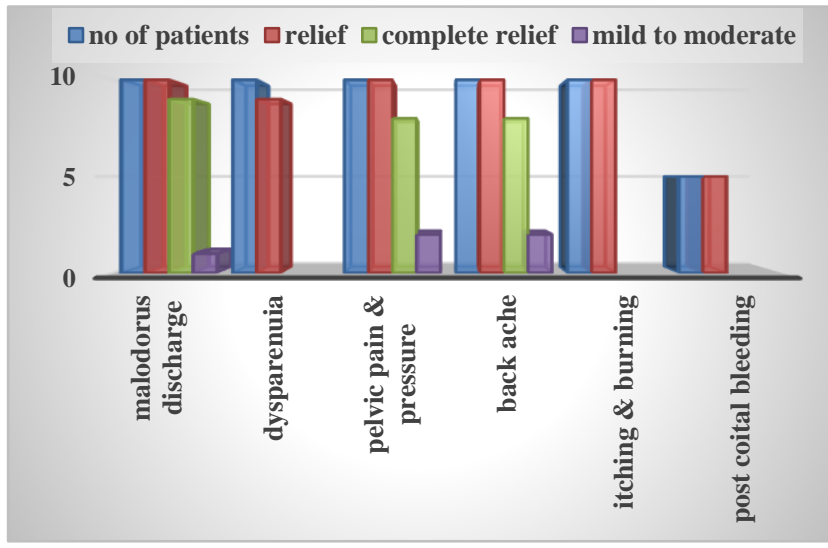

Figure 3: Symptom wise improvement in chronic cervicitis patients after stem cell therapy.

1 patient had severely eroded cervix, post treatment repeat biopsy of this patient showed persistence of inflammation. From cured patients one biopsy was repeated to confirm the result, shows reversal of inflammatory changes (Table2). Pap smear was taken at 3 , 6 and 12 months interval along with colposcopy showed no signs of inflammation and normal cervical cells and discharge, with healed erosion. No immediate or long term adverse effects were observed over 1 year except in one patient which showed short term immunological reaction like chills, mild fever and headache lasting for 1-2 days initially.

Table 2: Parameters of observation post treatment.

\begin{tabular}{|lllll|}
\hline Clinical symptoms & Pap test & Colposcopy & Biopsy & Result \\
\hline Improved 1 Pt. & Normal cells & Not so healthy cervix & repeated & Persistence of inflammation \\
\hline Cured 9 Pts. & Non-inflammatory & Health Cervix & 1biopsy repeated & Normal cells \\
\hline
\end{tabular}

\section{DISCUSSION}

Stem Cell Therapy is very specialized treatment for incurable, crippling and fatal diseases, then why a common disease like cervicitis is selected for SCT in our study. Because chronic infection and inflammation of cervix is the most commonly encountered disease in adult women worldwide with significant economical burden as 
disease is hard to cure with high recurrence rate due to repeated exposure to aetiology, weak immune system, and high risk sexual behaviour and under treatment. It severely impaired physical and mental health of a woman due to irritant, itchy, malodorus discharge per vaginum, dyspareunia, post coital bleeding hampering marital health, giving general sense of weakness, ill health and unhygienic feeling. So, these devastating symptoms and long term serious consequences especially predisposition to viral infections and cervical cancer lead to this concept study. As no current treatment available to reverse the damage to the cervix, alternative approach of AASCs plays a crucial role in cell protection, regeneration of epithelial tissues, repairing of fibrosed tissue, curing deep seated infection and inflammation, thus improving genital health, hygiene, immunity and general wellbeing. ${ }^{1}$

Stem cells are biological cells found in all multi-cellular organisms for repair and regeneration. It can divide and differentiate into diverse specialized cell types and can self-renew to produce more stem cells. ${ }^{1,4}$ SCT is like exploiting the natural potential of body. MSCs can home to nearly all inflammation sites, including ischemic myocardial tissues and wounded skin regions and once arriving at the site and surrounded by particular type of body tissue and chemicals the ASCs naturally recognise the need and purpose of their existence and trans differentiate into the tissue of homing. ${ }^{5}$ This is the very natural healing process that the body undergoes on its own. The biological characteristics that contribute to the therapeutic effects of MSCs after infusion are the ability to home in at the sites of inflammation following tissue injury, the ability to differentiate into various cell types, the ability to secrete multiple bioactive molecules which stimulates recovery of injured cells and inhibits inflammation, ability to perform immuno-modulatory functions with no immunogenicity and activation of endogenous progenitor cell. In fact it is the combined and overlapping effect of MSCs that gives therapeutic relief. ${ }^{6}$

Sexually transmitted infections and cancer impact significantly on global health and cervical cancer is the second most prevalent cancer in women worldwide. ${ }^{1,7} \mathrm{~A}$ substantial body of evidence supports the conclusion that chronic inflammation can predispose an individual to cancer, the longer the inflammation persists, the higher the risk of associated carcinogenesis. ${ }^{3}$ Most of the cervical carcinomas are associated with human papilloma-virus (HPV) as rate of HPV and HIV infection in chronic cervicitis cases is much higher as observed by Ealhe, Atsuki et al in his study of CSC noticed that interactions between MSCs and tumor cells in tumor tissues could become a new cancer therapy target. ${ }^{7-10}$

Autologus stem cell therapy can emerge as a potential treatment strategy for chronic cervicitis, with promising result for inflamed and damaged cervical tissue. As treatment with AASCs showed reversal of chronic inflammatory changes with healing of erosions, improved symptoms and better cervical health with improved quality of life and well-being, in long term prevention from Ca Cervix is expected. ${ }^{11-13}$ AASCs are easy to obtain, do not have any immunogenic complication and ethical issues. ${ }^{14,15}$ This treatment can reverse as well as stop further damage caused to cervix due to irritation or infection. Further clinical studies in this technique is needed that take into account the results obtained from case study as observed here, but early results are promising.

Future of SCT in Ob/GYNE management of cancer cervix, stress urinary incontinence (SUI) vesico vaginal fistula (VVF) repair, infertility management by regeneration of ovary, endometrial regeneration in Ashermans syndrome, development of hypolplastic uterus and bio-substitute for replacement. ${ }^{13,16,17}$ In utero transfer of SCs for management of congenital disease is under research. ${ }^{18}$ Menstrual blood is a potential source for obtaining autologus stem cell in future as observed in the study of Patel at al. ${ }^{14}$

\section{Funding: No funding sources \\ Conflict of interest: None declared}

Ethical approval: The study was approved by the Institutional Ethics Committee

\section{REFERENCES}

1. Lusk MJ, Konecny P. Cervicitis: a review. Curr Opinion Infect Dis. 2008;21:49-55.

2. Boccardo E, Lepique AP, Villa LL. The role of inflammation in HPV carcinogenesis. Carcinogenesis. 2010;31(11):1905-12.

3. Keibel A, Singh V, Sharma MC. Inflammation, microenvironment, and the immune system in cancer progression. Curr Pharma Des. 2009;15(17):1949-55.

4. Li L, Xie T. Stem cell niche: structure and function. Annu Rev Cell Dev Biol. 2005;21:605-31.

5. Maxson S, Lopez EA, Yoo D, DanilkovitchMiagkova A, Leroux MA. Concise review: role of mesenchymal stem cells in wound repair. Stem Cells Transl Med. 2012;1(2):142-9.

6. Meirelles Lda S, Fontes AM, Covas DT, Caplan AI. Mechanisms involved in the therapeutic properties of mesenchymal stem cells. Cytokine Growth Factor Rev. 2009;20(5-6):419-27.

7. Kogan EA, Fayzullina NM, Demura TA, Sukhikh GT. Reparative Spheroids in HPV-Associated Chronic Cervicitis. Int J BioMed. 2013;3(3):192-6.

8. Mirzaie-Kashani E, Bouzari M, Talebi A, Arbabzadeh-Zavareh F. Detection of human papillomavirus in chronic cervicitis, cervical adenocarcinoma, intraepithelial neoplasia and squamus cell carcinoma. Jundishapur J Microbiol. 2014;7(5):e9930.

9. Malecki M. Above all, do no harm:safeguarding pluripotent stem cell therapy against iatrogenic tumorigenesis. Stem Cell Res Therapy. 2014;5(3):73

10. Sato A, Ishiwata $\mathrm{T}$, Matsuda $\mathrm{Y}$, Yamamoto $\mathrm{T}$, Asakura H, Takeshita $\mathrm{T}$ et al. Expression and role of 
nestin in human cervical intraepithelial neoplasia and cervical cancer. Int J Oncol. 2012;41(2):441-8.

11. Lane FL, Jacobs S. Stem cells in gynecology. AJOG. 2012;207 (3):149-56.

12. Kato K. Stem cells in human normal endometrium and endometrial cancer cells; Charecterization of side population cells. Kaohsiung $\mathrm{J}$ Med Sci. 2012;28(2):63-71.

13. Liu XF, Yang WT, Xu R, Liu JT, Zheng PS. Cervical cancer cells with positive SOX 2 expression exhibit the properties of cancer stem cells. PLoS One. 2014;9(1):e87092.

14. Patel AN, Parke, Kuzman M, Banetti F, Silva F. Multipotent menstrual blood stromal stem cells: isolation, charecterization and differentiation. Cell Trans plant. 2008;17(3):303-11.

15. Blanpain C, Fuchs E. Plasticity of epithelial stem cells in tissue regeneration. Science. 2014;344(6189):1242281.
16. Oh IH, Snyder EY. Special feature on stem cells: current research and future prospects. Exp Mol Med. 2013;45:e63.

17. Verdi J, Tan A, Shoae-Hassani A, Seifalian AM. Endometrial stem cells in regenerative medicine. J Biol Eng. 2014;8:20.

18. Shaw SW, David AL, De Coppi P. Clinical applications of prenatal and postnatal therapy using stem cells retrieved from amniotic fluid. Curr Opinion Obstet Gynecol. 2011;23(2):109-16.

Cite this article as: Jain M, Jain S. Chronic cervicitis: role of adult autologus stem cells. Int J Reprod Contracept Obstet Gynecol 2017;6:2202-6. 